\title{
Association of Perioperative Whole Blood Transfusion with Troponin I Release after Off-Pump Coronary Artery Bypass Surgery
}

\author{
MAHFUZA BEGUM ${ }^{1}$, RAMPADA SARKER ${ }^{1}$, MD. KAMRUL HASAN ${ }^{1}$, TANVEER ZAMAN ${ }^{2}$, HOSNE JAHAN ${ }^{3}$, \\ SABRINA SHARMIN HUSSAIN ${ }^{1}$ ASIT BARAN ADHIKARY ${ }^{4}$
}

${ }^{1}$ Dept. of Cardiac Surgery, National Institute of Cardiovascular Diseases (NICVD), Dhaka, Bangladesh, ${ }^{2}$ Dept. of Cardiac Surgery, Bangladesh Specialized Hospital, Dhaka, Bangladesh, ${ }^{3}$ Dept. of Microbiology, Shaheed Suhrawardi Medical College, Dhaka, Bangladesh, ${ }^{4}$ Dept. of Cardiac Surgery, Bangabandhu Sheikh Mujib Medical University (BSMMU), Dhaka, Bangladesh

Address for Correspondence: Dr. Mahfuza Begum, Postgraduate fellow of Cardiac Surgery, National Institute of Cardiovascular Diseases (NICVD), Dhaka, Bangladesh. Email: mbegum.nayan@yahoo.com

\begin{abstract}
:
Background: Increased postoperative levels of Troponin I (TnI) after Off-pump Coronary Artery Bypass Grafting (OPCABG) surgery can often be observed in patients in the absence of significant perioperative hemodynamic instability or any evident intra-operative technical problems or signs of graft failure. A study undertaken by Biancari and his collegues (2012) found that Red Blood Cell transfusion was associated with increased TnI release after elective OPCABG ${ }^{1}$. Serum TnI level is an established indicator of myocardial injury. This prospective observational study was conducted in the Department of Cardiac Surgery, National Institute of Cardiovascular Diseases and Department of Cardiac Surgery, Bangabandhu Sheikh Mujib Medical University (BSMMU), Dhaka, Bangladesh, from January 2015 to December 2016 to assess whether intraoperative and immediate postoperative Whole Blood Transfusion resulted in increased release of TnI after isolated OPCABG operation.

Materials \& Methods: Atotal of 40 patients (34 males and 6 females) undergoing OPCABG were consecutively enrolled in the study, 20 patients in the transfusion recipient group and 20 patients in the non-transfusion recipient group. The groups were compared for pre-operative baseline characteristics and co-morbidities, per-operative techniques and events, and postoperative or end-point variables including Postoperative TnI level measured 12 hours at the end of surgery and a number of other clinical outcomes.

Results: Both transfusion recipient and non-transfusion recipient groups had statistically indifferent baseline characteristics, co-morbidity counts, operative techniques and operative events. No significant difference ( $\mathrm{p}=1.000)$ was noted in case-counts with increased Postoperative TnI level between the groups (85\% in the transfusion recipient group versus $90 \%$ in the non-transfusion recipient group). All other clinical outcomes were also found to be similarly distributed with no statistical difference between the groups.

Conclusion: In contrast to Red Blood Cell transfusion in several other studies, perioperative Whole Blood transfusion was not associated with increased postoperative Troponin I (TnI) release after isolated offpump coronary artery bypass grafting (OPCABG) operation.
\end{abstract}

Key words: Blood transfusion, Troponin I, OPCABG.

University Heart Journal 2017; 13(2): 55-58

Introduction:

Nearly half of the patients undergoing coronary artery bypass grafting $(\mathrm{CABG})$ are exposed to Red Blood Cell (RBC) products. Although large volumes (3+ units) of transfusions are typically given to preserve life in cases of acute blood loss, smaller quantities may be potentially avoidable. ${ }^{2}$
Published researches suggest that patients exposed to even 1 to 2 units of RBCs may have a 2.44 times unadjusted \& 1.86 times propensity adjusted increase in mortality. In addition, sternal wound infection, stroke, renal failure, new-onset dialysis, atrial ûbrillation, reoperation for bleeding, prolonged ventilation time $>24$ hours, total intensive care unit stay $>24$ hours, postoperative length 
of stay $>7$ days were also found to be significantly associated with perioperative blood transfusion. ${ }^{3}$

In addition, $\mathrm{RBC}$ transfusion has been found to be associated with pnrumonia, ${ }^{2}$ blood stream infections ${ }^{4}$, low-output graft heart failure, ${ }^{5}$ increased hazard of graft occlusion. ${ }^{6}$

Myocardial injury after coronary artery bypass graft surgery (CABG), as measured by cardiac biomarkers is associated with a signiûcantly higher risk of early and late mortality. ${ }^{7}$ In particular, cardiac Troponin I (TnI) seems to be the most accurate biomarker of myocardial injury after cardiac surgery. 8,9

A study undertaken by Biancari and his collegues (2012) found that Red Blood Cell transfusion was associated with increased TnI release after elective Off-pump CABG (OPCABG) surgery, independent of haemoglobin and haematocrit nadirs. ${ }^{1}$

Pathophysiological explanation is that, the reduced deformability of stored RBCs, which may result in occlusion of the microcirculation by nondeformable RBCs is ineffective in salvaging ischaemic myocardium. ${ }^{1}$ In addition, stored RBCs have lower adenosine triphosphate (ATP) levels and impaired ability to release it in the micro-circulation. Therefore, the potent ATP-related vasodilatory effect is suboptimal. ${ }^{10}$ The high free haemoglobin concentrations measured in stored RBC may further affect microcirculation because free haemoglobin has a potent nitric oxide (Endothelium Derived Relaxation Factor) scavenging ability, and this may induce vasoconstriction and worsen the ischemic injury. ${ }^{11}$

The present research is aimed at observing whether similar phenomenon of increased TnI release takes place when Whole Blood is transfused instead of RBC during the perioperative period of OPCABG.

\section{Methods:}

This prospective observational study was performed at the Department of Cardiac Surgery, National Institute of Cardiovascular Diseases (NICVD) and the Department of Cardiac Surgery, Bangabandhu Sheikh Mujib Medical University (BSMMU), Dhaka, Bangladesh, from January 2015 to December 2016. A Total of 40 patients undergoing isolated OPCABG, 20 in the transfusion recipient group and 20 in the non-transfusion recipient group were enrolled consecutively. TnI levels were measured for all patients 12 hours after the end of operation. Statistical analysis was done using SPSS version 19.

\section{Results:}

There were no statistically significant differences between the two groups in any of the baseline, preoperative or postoperative characteristics.

Table-I

Baseline Characteristics

\begin{tabular}{|c|c|c|c|}
\hline Variable & $\begin{array}{c}\text { Transfusion } \\
\text { recipient }(n=20)\end{array}$ & $\begin{array}{l}\text { Non-transfusion } \\
\text { recipient }(n=20)\end{array}$ & $P$ value \\
\hline Age (years) $)^{\#}$ & $55.85 \pm 8.34$ & $55.50 \pm 8.847$ & 0.898 \\
\hline Age $>60$ years ${ }^{2 \%}$ & $5(25.0 \%)$ & $5(25.0 \%)$ & 1.000 \\
\hline Female Sex & $4(20.0 \%)$ & $2(10.0 \%)$ & 0.661 \\
\hline Body Mass Index $\left(\mathrm{kg} / \mathrm{m}^{2}\right)^{\#}$ & $24.72 \pm 3.16$ & $23.74 \pm 3.01$ & 0.325 \\
\hline Obese (BMIe"30)" & $1(5.0 \%)$ & $1(5.0 \%)$ & 1.000 \\
\hline Hypertension $^{2 \%}$ & $11(55.0 \%)$ & $9(45.0 \%)$ & 0.342 \\
\hline Respiratory disease" & $0(0.0 \%)$ & $2(10.0 \%)$ & 0.487 \\
\hline Diabetes mellitus ${ }^{2 \%}$ & $11(55.0 \%)$ & $8(40.0 \%)$ & 0.342 \\
\hline History of cardiogenic shock & $0(0.0 \%)$ & $0(0.0 \%)$ & $n / a$ \\
\hline NYHA III/IV status $\%$ & $14(70.0 \%)$ & $12(60.0 \%)$ & 0.507 \\
\hline EuroSCORE II ${ }^{\& !}$ & $2.00($ IQR $0.99-2.70)$ & $1.55($ IQR $0.94-2.05)$ & 0.185 \\
\hline Impaired LVEF(30-49\%) & $7(35.0 \%)$ & $8(40.0 \%)$ & 0.744 \\
\hline Single Vessel Disease & $0(0.0 \%)$ & $0(2.0 \%)$ & $n / a$ \\
\hline Double Vessel Disease ${ }^{2 \%}$ & $5(25.0 \%)$ & $6(30.0 \%)$ & 0.723 \\
\hline Triple Vessel Disease ${ }^{2 \%}$ & $15(75.0 \%)$ & $14(70.0 \%)$ & 0.723 \\
\hline e" $50 \%$ left main stenosis " & $4(20.0 \%)$ & $4(20.0 \%)$ & 1.000 \\
\hline
\end{tabular}

\# Data analyzed using Student's t test.\&! median and interquartile range (IQR) are given due to skewed distribution of data. Data analyzed using Mann-Whitney U test. ${ }^{2 \%}$ Data analyzed using Chi-square test.” Data analyzed using Fisher's exact test. 
Table-II

Preoperative Troponin I, Haemoglobin and Haematocrit levels

\begin{tabular}{lccc}
\hline Variable & Transfusion recipient $(\mathrm{n}=20)$ & Non-transfusion recipient $(\mathrm{n}=20)$ & P value \\
\hline Troponin I $(\mathrm{ng} / \mathrm{ml})$ !! & $0.0175(\mathrm{IQR} 0.0100-0.0207)$ & $0.0178(\mathrm{IQR} 0.0100-0.0280)$ & 0.580 \\
Haemoglobin $(\mathrm{gm} / \mathrm{dl})^{\#}$ & $11.6 \pm 1.34$ & $12.1 \pm 3.02$ & 0.232 \\
Haematocrit $(\%)^{\#}$ & $34.9 \pm 4.02$ & $36.3 \pm 2.79$ & 0.231 \\
\hline
\end{tabular}

$\&$ ! median and interquartile range (IQR) are given due to skewed distribution of data. Data analyzed using Mann-Whitney U test.\# Data analyzed using Student's t test.

Table-III

Peroperative variables

\begin{tabular}{lccc}
\hline Variable & Transfusion recipient $(\mathrm{n}=20)$ & Non-transfusion recipient $(\mathrm{n}=20)$ & P value \\
\hline Total number of grafts \&! & 3.3 (IQR 3.0-4.0) & $3.2(\mathrm{IQR} 3.0-3.0)$ & 0.437 \\
Operation time (min) $\& !$ & 240.0 (IQR 211.2-253.7 & $240.1(\mathrm{IQR} 225.7-253.7)$ & 0.329 \\
IABP use & $0(0.0 \%)$ & $0(0.0 \%)$ & $n / a$ \\
Conversion to CPB & $0(0.0 \%)$ & $0(0.0 \%)$ & $n / a$ \\
Cardiac Arrest $^{-.}$ & $0(0.0 \%)$ & $0(0.0 \%)$ & $n / a$ \\
\hline
\end{tabular}

$\& !$ median and interquartile range (IQR) are given due to skewed distribution of data. Data analyzed using Mann-Whitney U test." Data analyzed using Fisher's exact test.

Table-IV

Postoperative ThI levels

\begin{tabular}{lccc}
\hline Variable & Transfusion recipient $(\mathrm{n}=20)$ & Non-transfusion recipient $(\mathrm{n}=20)$ & P value \\
\hline Raised TnI" & $17(85.0 \%)$ & $18(90.0 \%)$ & 1.000 \\
\hline
\end{tabular}

" Data analyzed using Fisher's exact test.

Table-V

Postoperative adverse clinical outcomes

\begin{tabular}{|c|c|c|c|}
\hline Variable & $\begin{array}{l}\text { Transfusion } \\
\text { recipient }(n=20)\end{array}$ & $\begin{array}{l}\text { Non-transfusion } \\
\text { recipient }(\mathrm{n}=20)\end{array}$ & $P$ value \\
\hline Reopening" & $1(5.0 \%)$ & $0(0.0 \%)$ & 1.000 \\
\hline Cardiac arrest" & $0(0.0 \%)$ & $0(0.0 \%)$ & $n / a$ \\
\hline Perioperative MI" & $0(0.0 \%)$ & $0(0.0 \%)$ & $n / a$ \\
\hline Renal failure/ Dialysis" & $1(5.0 \%)$ & $0(0.0 \%)$ & 1.00 \\
\hline Respiratory complication" & $2(10.0 \%)$ & $0(0.0 \%)$ & 0.487 \\
\hline High inotrope support" & $2(10.0 \%)$ & $1(5.0 \%)$ & 1.000 \\
\hline IABP support" & $0(0.0 \%)$ & $0(0.0 \%)$ & $n / a$ \\
\hline Arrhythmia" & $3(15.0 \%)$ & $1(5.0 \%)$ & 0.605 \\
\hline Wound infection" & $3(15.0 \%)$ & $2(10.0 \%)$ & 1.000 \\
\hline Ventilation time $(\mathrm{hr})^{\#}$ & $12.71 \pm 2.12$ & $11.95 \pm 2.40$ & 0.292 \\
\hline Prolonged ventilation $>24 \mathrm{hr}$." & $1(5.0 \%)$ & $0(0.0 \%)$ & 1.000 \\
\hline ICU stay (hr.) ${ }^{\& !}$ & $46.16($ IQR $28.75-47.18)$ & $39.74(\mathrm{IQR} 26.83-45.37)$ & 0.279 \\
\hline Prolonged ICU stay $>48 \mathrm{hr} . "$ & $4(20.0 \%)$ & $2(10.0 \%)^{\dagger}$ & 0.661 \\
\hline Postoperative hospital stay (days) ${ }^{\& !}$ & 7.7 (IQR $7.0-7.7$ ) & $7.3($ IQR $7.0-7.0)$ & 0.394 \\
\hline Prolonged Postop length of stay $>7$ days & $5(25.0 \%)$ & $3(15.0 \%)$ & 0.695 \\
\hline Readmission within 30 days" & $1(5.0 \%)$ & $0(0.00 \%)$ & 1.000 \\
\hline
\end{tabular}

\# Data analyzed using Student's t test.

. Data analyzed using Fisher's exact test.

$\& !$ median and interquartile range are given due to skewed distribution of data. Data analyzed using Mann-Whitney U test. 


\section{Discussion:}

In the present study, in off-pump coronary artery bypass grafting operation, perioperative Whole Blood Transfusion was not found to be associated with increased postoperative TnI release than non-transfusion, as measured by its level on first postoperative day.

This finding was in contrast to the findings of Biancari, et al. (2012) who found RBC transfusion to be significantly associated with increased $\mathrm{TnI}$ release after OPCABG. Operation time in the present study was $240.02 \pm 35.68$ minutes while in Biancari's (2012) study it was $211 \pm 49$ minutes. The mean number of grafts in the present study was $3.25 \pm 0.54$ while in Biancari's (2012) study it was $3.8 \pm 1$.

Similar to Biancari's (2012) study, none of the patients needed conversion to cardiopulmonary bypass. $15 \%$ of patients in the present study experienced low output syndrome similar to $15 \%$ of patients in Biancari's (2012) study.

In Biancari's (2012) study, the postoperative release of TnI on first postoperative day positively correlated significantly with the units of packed RBCs transfused (rho 0.188, $p=0.026$ ). Similarly, a significant correlation was observed in the present study between TnI release and Whole Blood Transfusion.

In discordance with the study conducted by Horvath, et. al. (2013) transfusion was not significantly associated with wound infection.

\section{Conclusion:}

The inference drawn from the results of this study disproves our study hypothesis that, transfusion of Whole Blood during the perioperative period of OPCABG is associated with significant increase in immediate postoperative troponin I level. In contrast to other similar studies, in which cases only Packed RBCs were transfused, Whole Blood seem to have less detrimental effect on postoperative myocardium. While packed RBCs tend to clog the microcirculation resulting in diminished blood flow to the myocardium, whole blood is less dense and more physiological in its constituent proportions.

\section{References:}

1. Biancari, F. and Kinnunen, E. Red blood transfusion Is associated with troponin release after off-pump coronary artery bypass grafting. Annals of Thoracic Surgery, 2012;94:1901-07.
2. Likosky, D.S., Paone, G., Zhang, M., Rogers, M.A.M., Harrington, S.D., Theurer, P.F., DeLucia, A., Fishstrom, A., Camaj, A., and Prager R.L. Red blood cell transfusions impact pneumonia rates after coronary artery bypass grafting. Annals of Thoracic Surgery, 2015;100:794-801.

3. Paone, G., Likosky, D.S., Brewer, R., Theurer, P.F., Bell, G.F., Cogan, C.M. and Prager, R.L. Transfusion of 1 and 2 units of red blood cells is associated with increased morbidity and mortality. Annals of Thoracic Surgery, 2014;97:87-94.

4. Horvath, K.A., Acker, M.A., Chang, H., Bagiella, E., Smith, P.K., Iribarne, A., Kron, I.L., Lackner, P., Argenziano, M., Ascheim, D.D. Gelijns, A.C., Michler R.E., Patten, D.V., Puskas, J.D. Blood transfusion and infection after cardiac surgery. Annals of Thoracic Surgery, 2013;95:2194-2201.

5. Surgenor, S.D., DeFoe, G.R., Fillinger, M.P., Likosky, D.S., Groom, R.C., Clark, C., Helm, R.E., Kramer, R.S., Leavitt, B.J., Klemperer, J.D., Krumholz, C.F., Westbrook, B.M., Galatis, D,J., Frumiento, C., Ross, C.S., Olmstead, E.M. and O'Connor, G.T. Intraoperative Red Blood Cell Transfusion During Coronary Artery Bypass Graft Surgery Increases the Risk of Postoperative Low-Output Heart Failure. Circulation, 2006;114 [suppl I]:I-43-I-48.

6. Engoren, M.C., Schwann, T.A., Jewell, E., Neill, S., Benedict, P., Likosky, D.S. and Habib, R.H. Is transfusion associated with graft occlusion after cardiac operations? Annals of Thoracic Surgery, 2015;99:502-08.

7. Domanski, M.J., Mahaffey, K., Hasselblad, V., Brener, S.J., Smith, P.K., Hillis, G., Engoren, M., Alexander, J.H. Association of myocardial enzyme elevation and survival following coronary artery bypass graft surgery. Journal of American Medical Association, 2011;305:585-591.

8. Pegg, T.J., Maunsell, Z., Karamitsos, T.D., Taylor, R.P., James, T., Francis, J.M., Taggart, D.P., White, H., Neubauer, S., Selvanayagam, J.B. Utility of cardiac biomarkers for the diagnosis of type V myocardial infarction after coronary artery bypass grafting: insights from serial cardiac MRI. Heart, 2011;97:810-16.

9. Lim, C.C.S., Cuculi, F., Gaal, W.J.V., Testa, L., Arnold, J.R., Karamitsos, T., Francis, J.M., Digby, J.E., Antoniades, C., Kharbanda, R.K., Neubauer, S., Westaby, S., and Banning, A.P. Early Diagnosis of Perioperative Myocardial Infarction After Coronary Bypass Grafting: A Study Using Biomarkers and Cardiac Magnetic Resonance Imaging. Annals of Thoracic Surgery, 2011;92:2046-2053.

10. Hu, H., Xenocostas, A., Chin-Yee, N., Lu, X., Chin-Yee, I., Feng, Q. Transfusion of fresh but not old stored blood reduces infarct size and improves cardiac function after acute myocardial infarction in anemic rats. Critical Care Medicine, 2012;40:740-46.

11. Donadee, C., Raat, N.J., Kanias, T., Tejero, J., Lee, J.S., Kelly, E.E., Jhao, X., Liu, C. Nitric oxide scavenging by red blood cell microparticles and cell-free haemoglobin as a mechanism for the red cell storage lesion. Circulation, 2011;124:465-76. 